\title{
Epitaxial regrowth of InP/InGaAs heterostructure on patterned, nonplanar substrates*
}

\author{
ŁUKASZ KOSIOR ${ }^{\dagger}$, DAMIAN RADZIEWICZ, IWONA ZBOROWSKA-LINDERT, ANDRZEJ STAFINIAK, \\ MikoŁaJ BADURA, Beata ŚCIANA
}

Faculty of Microsystem Electronics and Photonics, Wrocław University of Technology,

Janiszewskiego 11/17, 50-372 Wrocław, Poland

\begin{abstract}
The main goal of the studies on epitaxial regrowth process of $\mathrm{InP}$ on patterned substrates is to gain knowledge about growth rates and interface quality on various areas to improve the fabrication technology for future applications. Prepared samples were measured at every step of the process by scanning electron microscope (SEM), optical microscope with dark field and phase contrast modes, atomic force microscope (AFM) and also using optical profilometer WLI (White Light Interferometer). Fabrication steps were divided into three main groups. First was the epitaxial growth of $5 \mu \mathrm{m}$ thick InP layer. Next was patterning, which was made by applying a mask film on the epilayer. Shapes of the mesas after wet chemical etching with photoresist as a mask as well as the shapes of mesas slopes were irregular on the whole substrate area. These problems were solved by the use of silicon nitride mask. The mesas shapes and their slopes became then regular, independently of etching depth. Second fabrication step was etching of selected area. Couple of solutions were examined, but in details $\mathrm{HCl}: \mathrm{H}_{3} \mathrm{PO}_{4}$ mixture in various proportions, which gave the best results in mesas shapes and orientations relative to the substrate. After that, the etching mask material was removed from the epilayer using a buffered hydrofluoric acid (BHF). The last step was epitaxial regrowth. To see how the epitaxial growth process was performed on different areas of patterned substrate it was suggested using a "sandwich", which consisted of 50 layers of indium phosphide and indium gallium arsenide. This idea helped to understand the phenomena occurring during the epitaxial growth on that kind of substrate. The highest growth rate occurred on the top of the mesas and the lowest on their slopes. Described experiments are introduction to the studies on epitaxial growth of buried heterostructure $(\mathrm{BH})$.
\end{abstract}

Keywords: epitaxy; MOVPE; patterned substrate; wet etching; mask material

(C) Wroclaw University of Technology.

\section{Introduction}

The main goal of this work was to gain knowledge about growing III - V epitaxial layers on the patterned, nonplanar substrates in LP-MOVPE reactor (Aixtron CCS $3 \times 2$ inch MOVPE device). The research was focused on controlling the growth parameters. Issues related to indium phosphide, the parameters of LP-MOVPE technology and patterned substrate epitaxial growth were discussed.

Various techniques used in each fabrication step of patterned substrate epitaxy could be found in the literature. These techniques strongly depend on available apparatus and also on different types

\footnotetext{
*This paper was presented at XIII Seminar on Surfaces and Thin-Film-Structures, Szklarska Poręba, Poland, 2015.

${ }^{\dagger}$ E-mail: lukasz.kosior@pwr.edu.pl
}

of used devices (e.g. various types of MOVPE reactors). That is why in different papers different results are found and it is hard to find one universal solution.

Commonly used mask materials are silicon dioxide [1-3] and silicon nitride [4]. Huang et al. [5] have tested both $\mathrm{SiO}_{2}$ and $\mathrm{Si}_{3} \mathrm{~N}_{4}$ mask materials for etching, the same as for selective epitaxial regrowth, confirming no difference after measuring structures.

Many researchers use dry-etching methods (mostly reactive-ion etching (RIE)) on indium phosphide substrates [6] as it is one of the key technologies for achieving high geometrical accuracy and uniformity in full-size wafers production. This technique meets some disadvantages as well. In the literature [7], the authors reported that RIE could 
induce a damaged layer on the etched surface. To solve this, after dry-etching, the surface was chemically treated with a concentrated sulphuric acid solution. The high-quality interface between mesa and regrown InP has been reached after etching to a depth of more than $100 \mathrm{~nm}$.

Another common etching method is also chemical wet-etching. Taking into account future applications and advantages of this method we decided to use it. To achieve $\mathrm{V}$-shaped corrugations with $1 \mu \mathrm{m}$ depth $3 \mathrm{H}_{3} \mathrm{PO}_{4}: 1 \mathrm{HCl}: 1 \mathrm{H}_{2} \mathrm{O}$ solution was used [2]. To obtain various shapes of mesa stripes $1 \mathrm{HBr}: 1 \mathrm{HNO}_{3}: 1 \mathrm{H}_{2} \mathrm{O}$ solution was applied [5].

Parameters of epitaxial growth process on a patterned substrate are usually poorly described. The typical information is that the MOVPE epitaxial processes were carried out at low pressure. The value of pressure in MOVPE reactor ranges from $2 \mathrm{kPa}$ [6], through $4.7 \mathrm{kPa}$ and $8 \mathrm{kPa}[4,5]$, finishing at $10 \mathrm{kPa}$ [8]. To characterize different growth rates at various patterned substrate areas, Galeuchet et al. from IBM Research Division [8] used multiple heterostructures of InGaAs/InP. This idea has been used successfully in our work.

The goal of this work was the development of procedures of spatial formation of epitaxial InP layers by appropriate selection of mask material and wet chemical etching. For evaluation of the quality of InGaAs/InP heterostructures grown on the patterned substrate SEM characterization was applied. The knowledge achieved in this research will be used in future experiments of growing buried InP:Fe heterostructure which needs an additional mask material for selective epitaxy. Such heterostructure finds its application in quantum cascade lasers as a high thermal conductivity layer to remove the heat from the laser core, resulting in an increase in the device thermal stability.

\section{Experimental}

To fabricate a device, several technological steps are needed. They can be divided into three main groups such as substrate patterning, etching and epitaxy. In Fig. 1, the main steps of patterned substrate epitaxy are shown. First one is patterning of the substrate. Generally, it is performed by applying a mask film on the substrate, next, there is etching of selected area of the substrate and, at the end, removing the rest of the mask. The substrate prepared in this form is ready for epitaxial growth. Additionally, before substrate patterning process, the growth of epitaxial layer is carried out. The performed experiments were based on LP-MOVPE epitaxial growth of $5 \mu \mathrm{m}$ indium phosphide with TMIn (trimethylindium) and phosphine as gas sources on (1 000$)$ InP:S substrates.

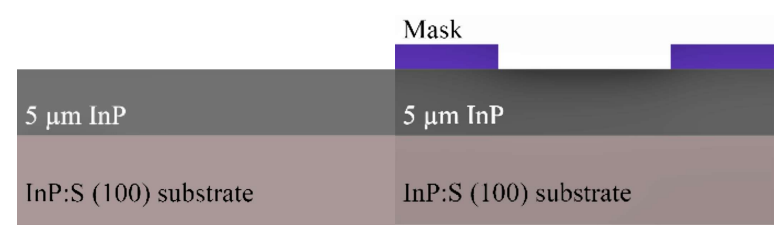

(I)

(II)

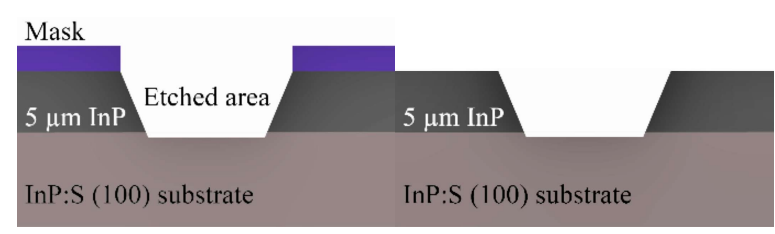

(III)

(IV)

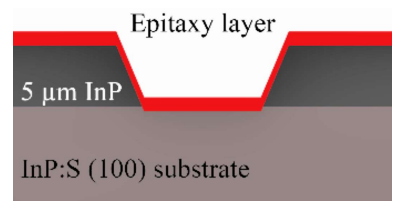

(V)

Fig. 1. Technological steps of patterned substrate epitaxy.

In the experiment, two masks: of photoresist and $\mathrm{Si}_{3} \mathrm{~N}_{4}$ were used. The mask pattern with rectangular and round shapes used in photolitography, is shown in Fig. 2 together with crystallographic directions marked for $\left(\begin{array}{lll}1 & 0 & 0\end{array}\right)$ substrate.

Silicon nitride layers were made by PECVD method (PlasmaLab 80 plus, Oxford Instruments) after epitaxy of $5 \mu \mathrm{m}$ InP layer. The $\mathrm{Si}_{3} \mathrm{~N}_{4}$ layer deposition process was based on the typical precursors, silane $\left(2 \% \mathrm{SiH}_{4}\right.$ in $\mathrm{N}_{2}$, flow $\left.1000 \mathrm{sccm}\right)$ and ammonia $\left(\mathrm{NH}_{3}, 7 \mathrm{~N}, 20 \mathrm{sccm}\right)$. The parameters of the deposition process were set as follows: temperature $250{ }^{\circ} \mathrm{C}$, pressure $86.66 \mathrm{~Pa}$, RF power $20 \mathrm{~W}$. 


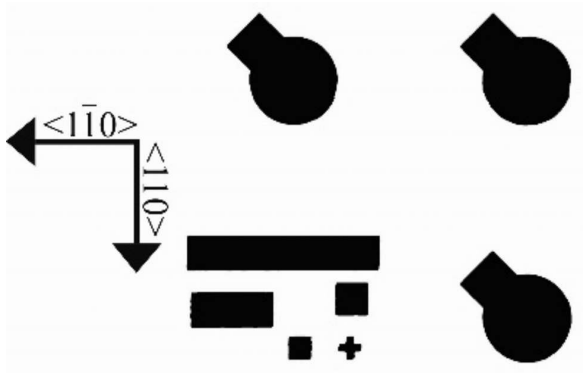

Fig. 2. Schematic view of the mask film and its arrangement in relation to crystallographic directions.

The thickness of the dielectric layers was $100 \mathrm{~nm}$. To define the ridge-waveguide pattern, the $\mathrm{Si}_{3} \mathrm{~N}_{4}$ layer was etched in BHF solution through a photoresist mask.

To examine the parameters such as etching ratio, mesa slopes shapes and select the best compound for indium phosphide etching, three different etching mixtures were used: $1 \mathrm{HCl}: 3 \mathrm{H}_{3} \mathrm{PO}_{4}$, $1 \mathrm{HCl}: 1 \mathrm{H}_{2} \mathrm{O}, 1 \mathrm{HCl}: 1 \mathrm{CH}_{3} \mathrm{COOH}: 1 \mathrm{H}_{2} \mathrm{O}_{2}$. The etching processes lasted 5 minutes.

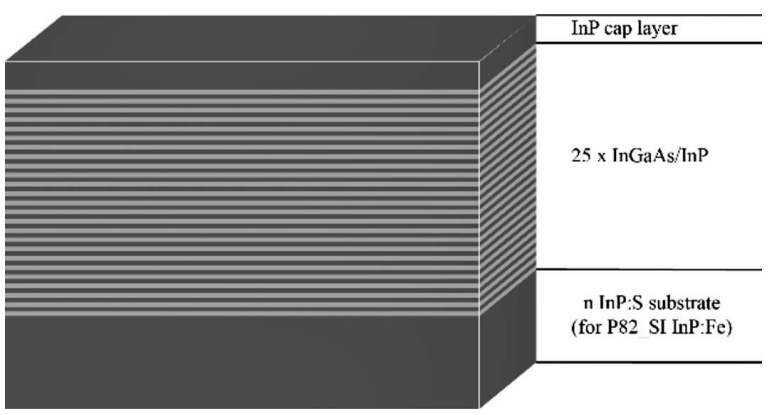

Fig. 3. Schematic view of structure applied in the regrowth process.

As a part of this work two InP epitaxial processes on patterned substrates were performed. The processes used the same procedure in the LP-MOVPE device. To determine the layer thicknesses from SEM images and the growth rates at different locations of the substrate, heterostructures composed of $25 \mathrm{InGaAs} / \mathrm{InP}$ were used. Each of the individual layers was intended to have a thickness of $100 \mathrm{~nm}$ under standard conditions, which should be fulfilled on smooth epi-ready planar surfaces. Fig. 3 schematically shows this structure.
For the epitaxial growth of the InGaAs layer, $\mathrm{V} / \mathrm{III}$ ratio was set to 60 . For the growth of the InP, V/III ratio was set to 333 . According to the assumption, these steps were repeated to produce a structure with the estimated thickness of $5 \mu \mathrm{m}$. In order to eliminate the problem of surface charging during SEM measurement, in the last stage of the process $500 \mathrm{~nm}$ InP layer was grown.

In this work, three samples fabricated in two epitaxial experiments (A and B) have been examined. Fabrication methods for the preparation of substrates to epitaxial growth process are shown in Table 1.

Table 1. Methods for the preparation of substrates for the epitaxial regrowth.

\begin{tabular}{ccc}
\hline Sample & Mask & Etching solution \\
\hline \hline A & Photoresist & \\
\cline { 1 - 1 } B1 & $1 \mathrm{HCl}: 1 \mathrm{H}_{3} \mathrm{PO}_{4}$ \\
\cline { 1 - 2 } B2 & SiN & \\
\hline
\end{tabular}

\section{Results}

After each experimental step, measurements with SEM, WLI or optical microscope were performed. To discuss the results obtained for different mask materials or wet chemical etching it was needed to collect data from each experimental step.

\subsection{Mask film}

After etching the structure in $1 \mathrm{HCl}: 3 \mathrm{H}_{3} \mathrm{PO}_{4}$ to a depth of about $2 \mu \mathrm{m}$ there were no significant differences between the materials used as the masks (Fig. 4a). This situation changed when the depth reached $10 \mu \mathrm{m}$ (Fig. 4b). The photoresist mask was underetched, forming rounded tops of the islands. Differences could be seen also in the slopes in $\left\langle\begin{array}{lll}1 & \overline{1} & 0\end{array}\right\rangle$ direction, which were not oriented according to the crystallographic planes where the shape of the mask edge was reproduced.

As can be seen in Fig. 5, the PECVD $\mathrm{Si}_{3} \mathrm{~N}_{4}$ layer served its purpose well. In the step of the hard mask forming, the dielectric layer was completely etched out without causing micro-masking effect in subsequent steps of etching. Moreover, during 


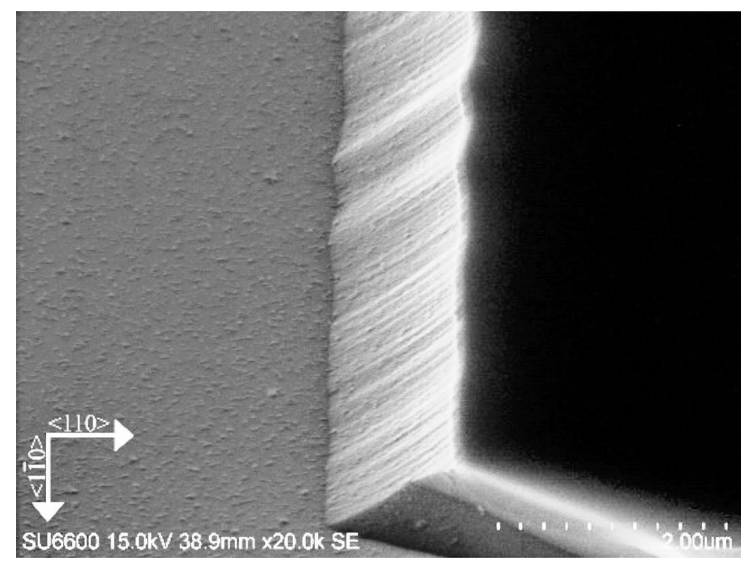

(a)

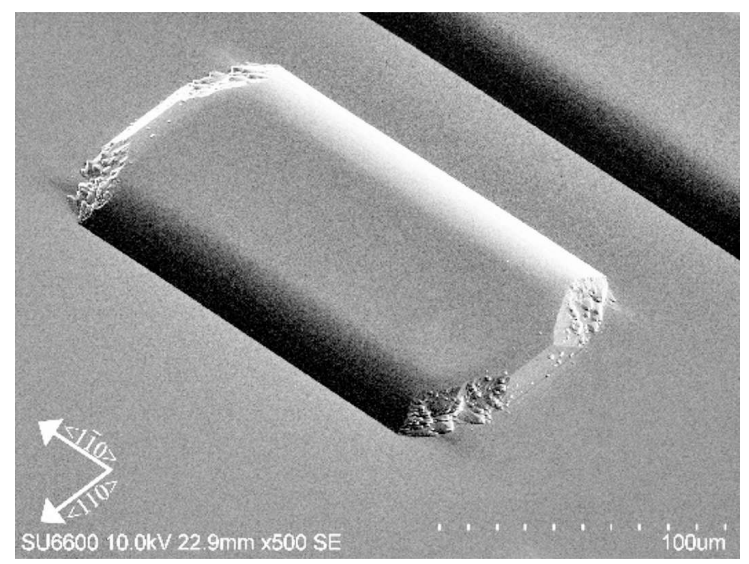

(b)

Fig. 4. SEM images of substrate after etching in $1 \mathrm{HCl}: 3 \mathrm{H}_{3} \mathrm{PO}_{4}$ solution with photoresist as a mask (a) $\sim 2 \mu$ m etching depth, (b) deep etching with photoresist mask already removed.

the etching process of epitaxial layer, the mask was chemically and mechanically stable which allowed creating the ridge-type structures.

The choice between the studied mask materials for patterned substrate epitaxy is significant. Quality of the surface after etching using photoresist is inferior to that obtained with silicon nitride mask. The difference between them is particularly noticeable at the edges of mesas and slopes that are rounded at a higher etching depth. It seems that using silicon nitride as a mask material solved this problem. The shapes of mesas were the same independently of etching depth. Silicon nitride can also be used in the future as a mask for selective epitaxy.

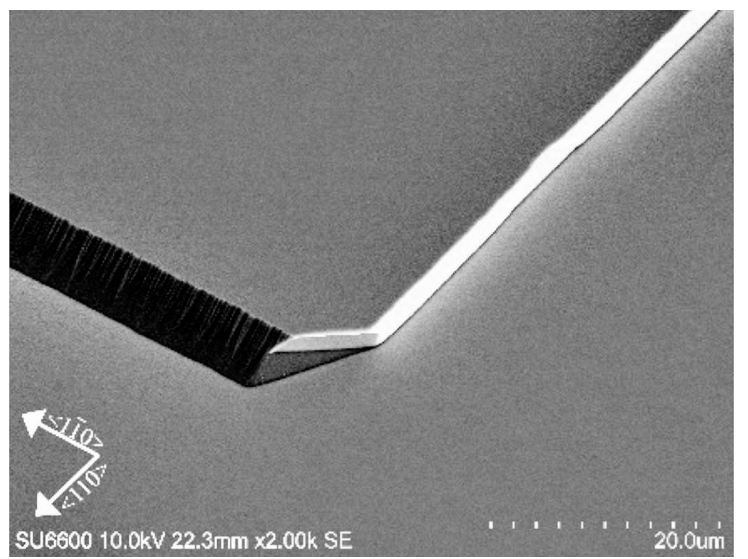

(a)

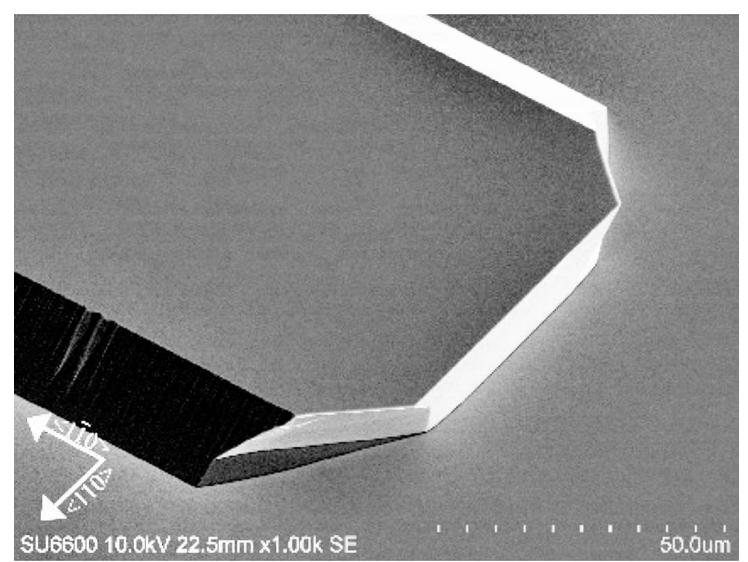

(b)

Fig. 5. SEM images of surface after etching in $1 \mathrm{HCl}: 3 \mathrm{H}_{3} \mathrm{PO}_{4}$ with $\mathrm{Si}_{3} \mathrm{~N}_{4}$ as a mask material (a) $\sim 2 \mu$ m etching depth, (b) $\sim 10 \mu$ m etching depth.

\subsection{Etching process}

Etching in $1 \mathrm{HCl}: 1 \mathrm{CH}_{3} \mathrm{COOH}: 1 \mathrm{H}_{2} \mathrm{O}_{2}$ for 5 minutes resulted in average depth of $15.42 \mu \mathrm{m}$ in WLI measurements (Fig. 6). Additionally, some deformations of the mesas shapes could be seen, which is observed in SEM pictures.

Etching in $1 \mathrm{HCl}: 1 \mathrm{CH}_{3} \mathrm{COOH}: 1 \mathrm{H}_{2} \mathrm{O}_{2}$ is unstable and difficult to control. Regardless of the crystallographic orientation, strong underetching of the mask occurred. In addition, the slope of the mesas descends to the centre, which is visible in Fig. 7.

Etching process in $1 \mathrm{HCl}: 1 \mathrm{H}_{2} \mathrm{O}$ for 5 minutes gave the structures which were better crystallographically oriented. The measured average depth was $3.42 \mu \mathrm{m}$. The mask was not damaged as in 


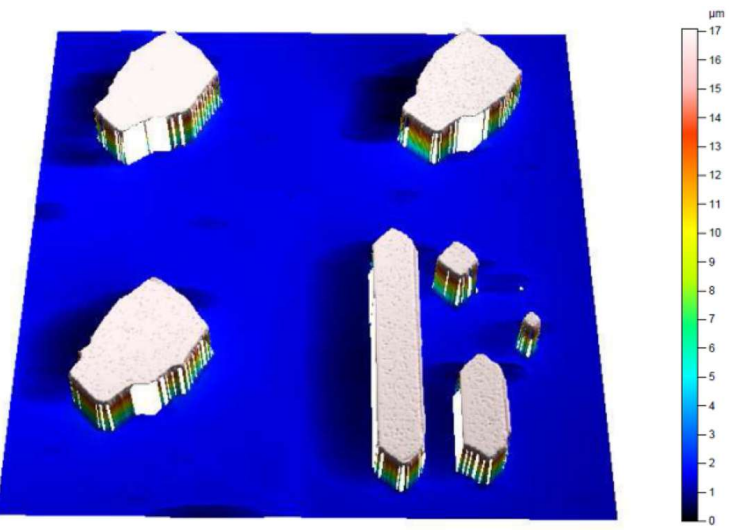

Fig. 6. WLI measurement result after 5 minute etching in $1 \mathrm{HCl}: 1 \mathrm{CH}_{3} \mathrm{COOH}: 1 \mathrm{H}_{2} \mathrm{O}_{2}$ solution.

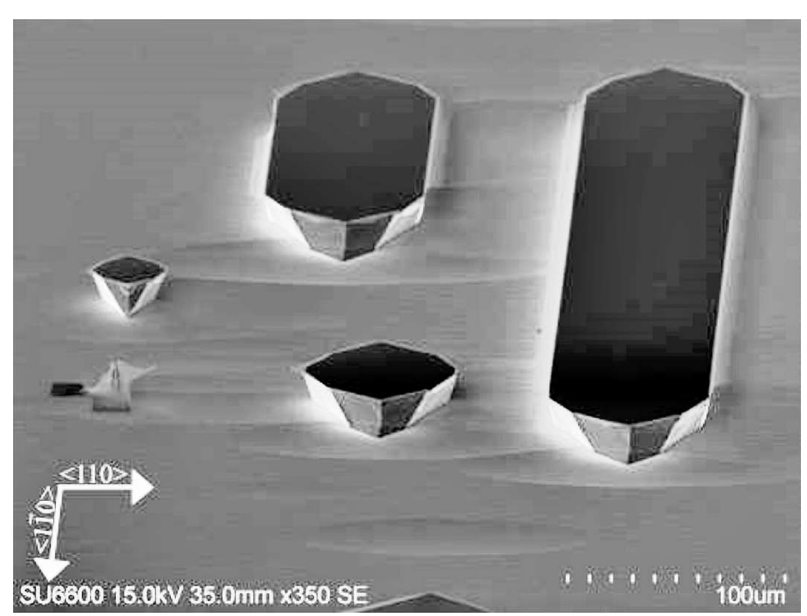

(a)

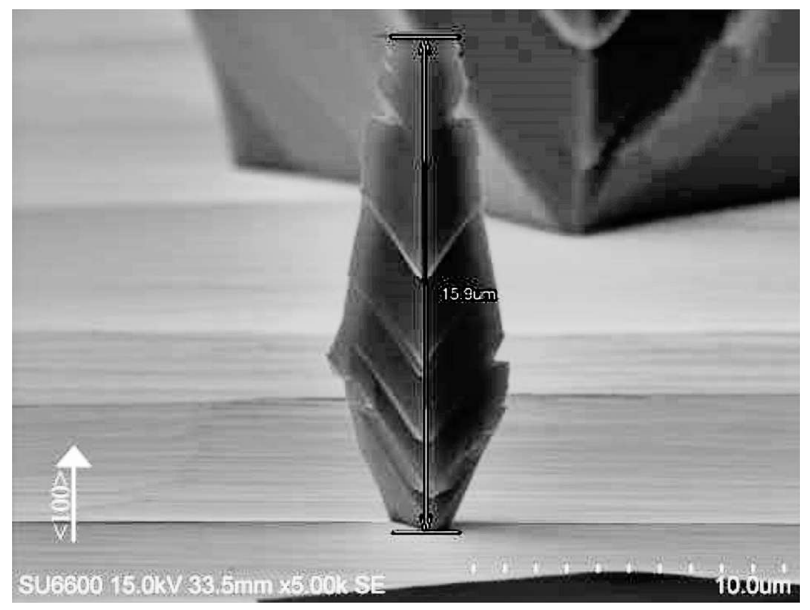

(b)

Fig. 7. SEM images of an InP substrate etched in $1 \mathrm{HCl}: 1 \mathrm{CH}_{3} \mathrm{COOH}: 1 \mathrm{H}_{2} \mathrm{O}_{2}$ (a) general view, (b) measured thickness of the etching. previously discussed solution. The gaps arranged in one direction $\left\langle\begin{array}{lll}1 & 1 & 0\end{array}\right\rangle$ visible in WLI picture are undesired (Fig. 8).

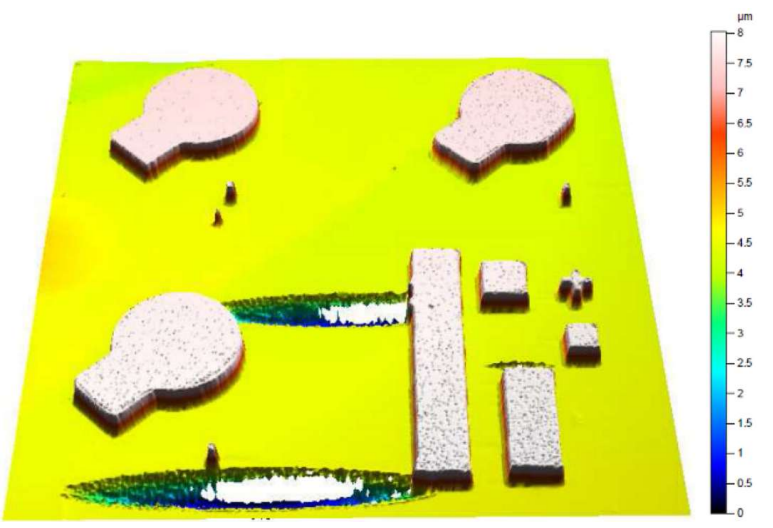

Fig. 8. WLI measurement result after 5 minute etching in $1 \mathrm{HCl}: 1 \mathrm{CH}_{3} \mathrm{COOH}: 1 \mathrm{H}_{2} \mathrm{O}_{2}$ solution.

Similar to the etching in $1 \mathrm{HCl}: 1 \mathrm{CH}_{3} \mathrm{COOH}: 1 \mathrm{H}_{2} \mathrm{O}_{2}$ mixture, underetching of the mask occurs, but not in all crystallographic orientations. The slopes of different inclinations relative to the substrate can also be distinguished (Fig. 9).

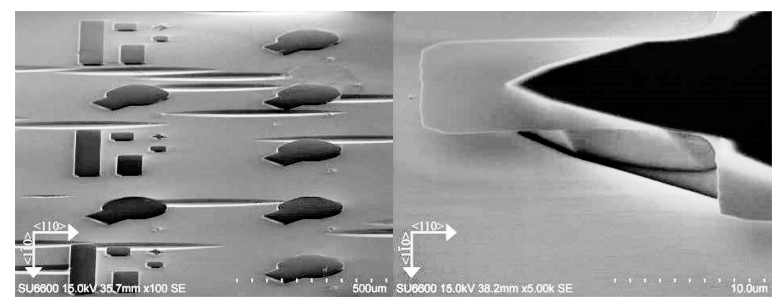

(a)

(b)

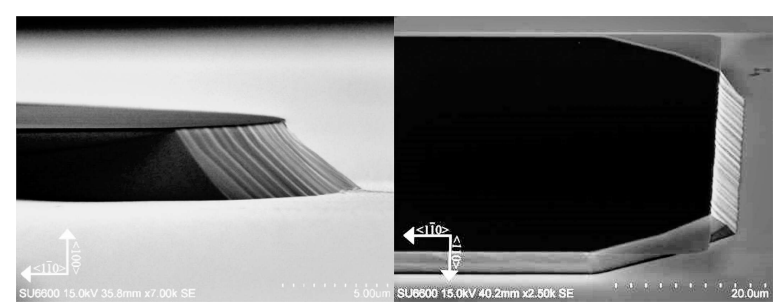

(c)

(d)

Fig. 9. SEM images of an InP substrate etched in $1 \mathrm{HCl}: 1 \mathrm{H}_{2} \mathrm{O}$ (a) general view with visible gaps, (b) part of 'cross' mask, (c) part of rounded mesa (d) slopes view. 
The best results were obtained after etching in $1 \mathrm{HCl}: 3 \mathrm{H}_{3} \mathrm{PO}_{4}$ mixture. Underetching is visible at the corners. Etching rate was nearly the same as in $1 \mathrm{HCl}: 1 \mathrm{H}_{2} \mathrm{O}$ solution. The process itself did not damage the mask, which is noticeable when measured by WLI (Fig. 10).
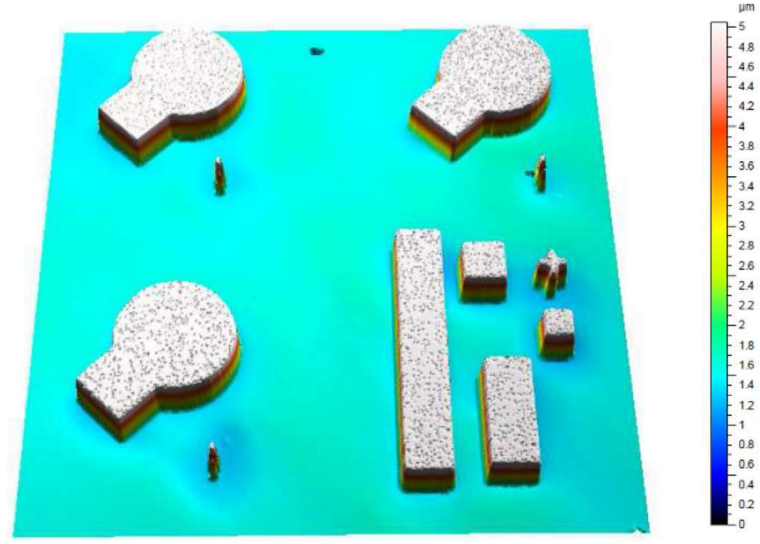

Fig. 10. Profilometer measurement results of 5 minute etching in $1 \mathrm{HCl}: 3 \mathrm{H}_{3} \mathrm{PO}_{4}$ mixture.

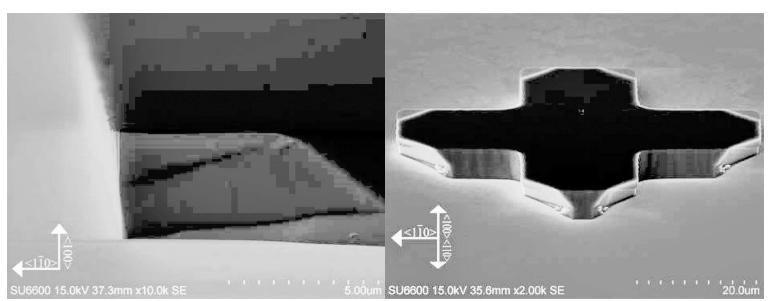

(a)

(b)

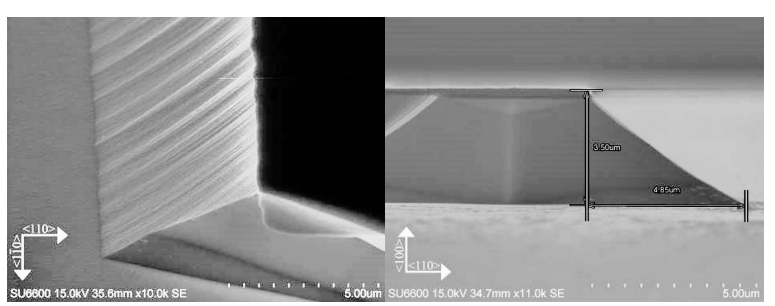

(c)

(d)

Fig. 11. SEM images of an InP substrate etched in $1 \mathrm{HCl}: 3 \mathrm{H}_{3} \mathrm{PO}_{4}$ (a) slope view, (b) 'cross' mask view, (c) slope in $\langle 1 \overline{1} 0\rangle$, (d) dimensions of $\left\langle\begin{array}{lll}1 & \overline{1} & 0\rangle \\ \text { slope. }\end{array}\right.$

The pictures taken with a scanning electron microscope highlights the underetching at the corners of the islands. It is also possible to measure the inclination of the slopes which are located in $\left\langle\begin{array}{lll}1 & 1 & 0\end{array}\right\rangle$ direction.

The depth after 5 minute etching in $1 \mathrm{HCl}: 3 \mathrm{H}_{3} \mathrm{PO}_{4}$ solution amounted to $3.5 \mu \mathrm{m}$. Since the method was considered as the best, it was decided to use it to prepare substrates for epitaxial regrowth. As a result of the chemical reaction of indium phosphide with a $1 \mathrm{HCl}: 3 \mathrm{H}_{3} \mathrm{PO}_{4}$ solution, strong gassing effect occurred. To release gas bubbles from the surface, ultrasounds were used during the etching process. Unfortunately, even then some surface defects could be seen, but small enough to be visible only by optical microscope in phase contrast (Fig. 12).

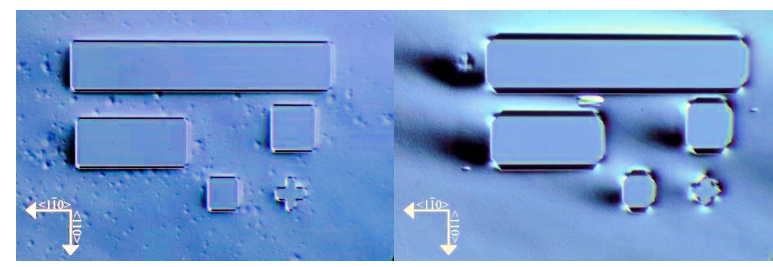

(a)

(b)

Fig. 12. Images taken with an optical microscope using a phase contrast technique (both from the same sample) (a) shallow etching site and (b) deep etching site.

As described above, the patterns etched in the studied solutions had different etching rates and slopes shapes, but $1 \mathrm{HCl}: 3 \mathrm{H}_{3} \mathrm{PO}_{4}$ appeared to provide the best parameters. For the next step, which was epitaxial regrowth, the samples were prepared using this solution.

\subsection{Patterned substrate epitaxy}

The samples were viewed under an optical microscope in the phase contrast and dark-field modes. The most striking thing in the pictures is the pleated surface at the slopes of the islands. The roughness has increased in the slopes area. There is also noticeable surface unevenness between the islands, but small enough to be not visible in images taken using dark-field method (Fig. 13).

After measurements with the optical microscope, incisions through the island in $\left\langle\begin{array}{lll}1 & 1 & 0\end{array}\right\rangle$ and 


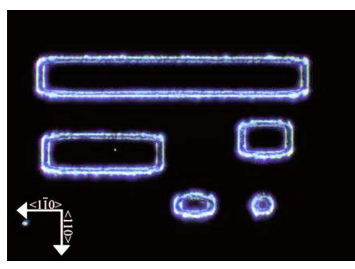

(a)

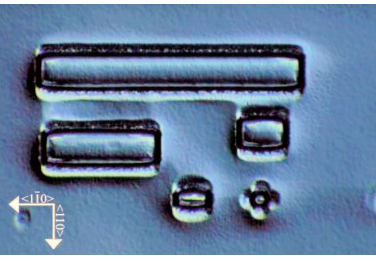

(b)
Fig. 13. Optical microscope images of P82 surface (a) dark field method and (b) phase contrast.

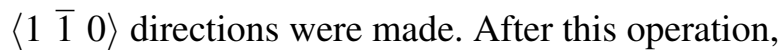
SEM measurements of sample cross section were performed.

Fig. 14 shows an incision in $\left\langle\begin{array}{lll}1 & 1 & 0\end{array}\right\rangle$ direction over the edge of the mesa. The edge is tilted at an angle of $22^{\circ}$ to the surface. Bright layer corresponds to the InGaAs material, InP is darker. White area in the picture at the top is due to charging the surface by the electron beam. The layer thicknesses vary on the slope. It is especially noticeable at the bottom. The layers are uneven, creating a wavy shape.

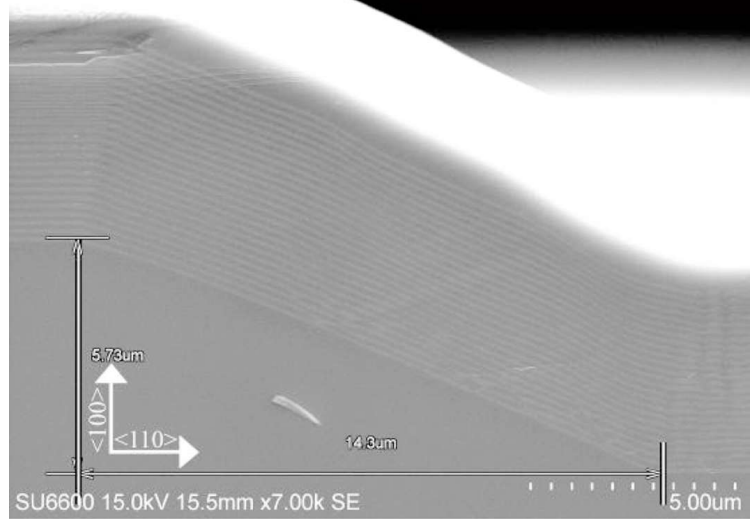

Fig. 14. SEM image of A sample cross-section.

Another element shown in Fig. 14 are defects that propagate through the crystal structure. They are best seen on the right side of the image, where they propagate upward, perpendicular to the substrate. Propagation traces at an angle to the substrate are also distinguished. Interestingly, these defects are not visible on the tops of the islands which were covered by the mask. This may explain inferior surface quality after the etching.
In the SEM images, the surface of the sample around the islands after patterned substrate epitaxy is characterized by high roughness. From Fig. 15, it can be seen that the shape of these distortions strongly depends on the slope and also that in every crystallographic plane the continuity of epitaxial growth is maintained.

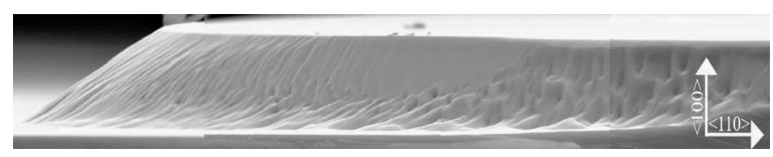

Fig. 15. Panoramic view of round shape mesa slope of sample A.

At the tops of the islands, the thickness of all applied layers after patterned substrate epitaxy was $6.2 \mu \mathrm{m}$. That means that for every couple of InGaAs/InP layers, the thickness would be about $209 \mathrm{~nm}$. The thickness of the layers in the space between the islands also departs from the assumed more than expected. Instead of planed $200 \mathrm{~nm}$ for the two layers it was measured to range from $180 \mathrm{~nm}$ to $190 \mathrm{~nm}$. The slope size decreased from about $170 \mathrm{~nm}$ to $154 \mathrm{~nm}$.

As can be seen in Fig. 16, the slopes surfaces are strongly waved. It does not stand in the way in a further application while the reused layer is intended as an insulating and thermally conducting material. However, it means that the surface may be of low-quality after etching process and that irregular epitaxial growth on the surfaces other than flat and parallel to the substrate may occur.

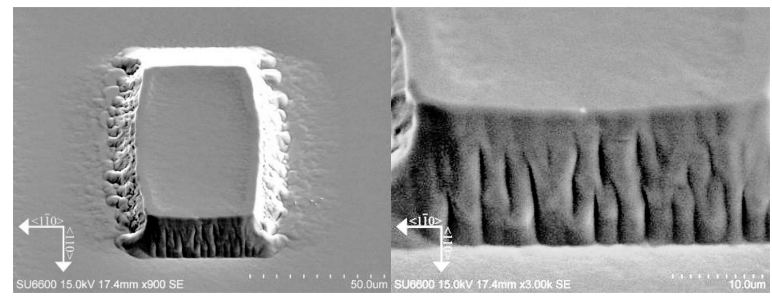

(a)

(b)

Fig. 16. SEM top view images of A sample.

In the second experiment of patterned substrate epitaxy "B", two samples (B1 and B2) were prepared similarly to the previous ones. The depth 
of etching was not uniform. For profiling B1 and B2 samples, photoresist and $\mathrm{Si}_{3} \mathrm{~N}_{4}$ masks were used, respectively.

B1 sample was used mainly to determine the regrowth process repeatability and compare the results with the sample B2, which was fabricated in the same process. Between A and B1 samples no significant differences were observed, so the repeatability of the process can be concluded as good. As regards the B2 sample, where the only difference with the other ones was the use of $\mathrm{Si}_{3} \mathrm{~N}_{4}$ mask, quality of the layers grown on the slopes improved.

Only the upper part of the slopes has visible unevenness, which results in a wavy shape of subsequent layers. However, there are no visible defects propagating neither in the substrate nor in the slopes (Fig. 17a and Fig. 17c). Etching depth in the studied area is larger than $10 \mu \mathrm{m}$. In comparison with the sample B1 with etching depth of $6 \mu \mathrm{m}$, an improvement of quality of the slopes of the regrown layers is evident. Deeper etching than in the sample A resulted in improving the quality of the surface between the islands, where propagating defects are not visible (Fig. 17).

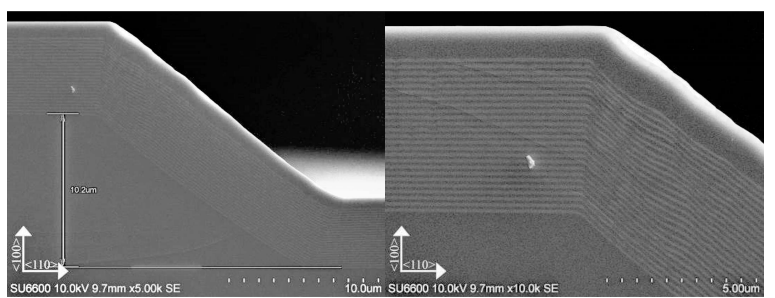

(a)

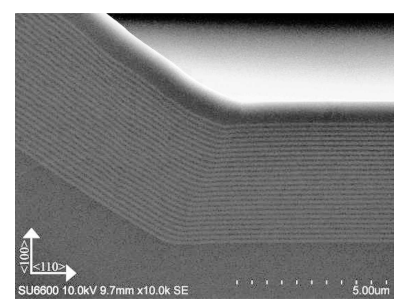

(b)

Fig. 17. SEM cross-section images of B2 sample.

Additional difference between etching with photoresist mask (Fig. 18a) and silicon nitride mask (Fig. 18b) is that the slopes along $\left\langle\begin{array}{lll}1 & 1 & 0\end{array}\right\rangle$ direction are perpendicular to the substrate only after etching with $\mathrm{Si}_{3} \mathrm{~N}_{4}$ mask.

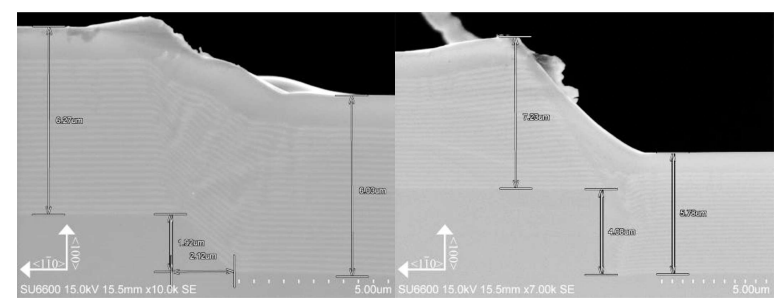

(a)

(b)

Fig. 18. SEM images of the same area in (a) B1 and (b) B2 samples.

\section{Conclusions}

\subsection{Mask material}

In this work, two mask materials have been studied. It has been found, that the quality of the surface after etching using photoresist mask is inferior comparing to that obtained with silicon nitride mask. The difference is particularly noticeable at the edges of mesas and slopes that are rounded for structures with greater depth. This problem was solved by using silicon nitride as the mask material. The shape did not change after etching process. The quality of the mesas slopes and also their shapes were the same for various etching depths. Additionally, silicon nitride can be used as a mask in selective epitaxy process. The benefits are the reason to choose $\mathrm{Si}_{3} \mathrm{~N}_{4}$ as the best material for patterned substrate epitaxy, just like for the selective epitaxial growth.

\subsection{Etching solution}

Several etching solutions have been tested on indium phosphide substrates. Every mixture caused a different etching rate and slope shapes. For epitaxial regrowth $\mathrm{HCl}: \mathrm{H}_{3} \mathrm{PO}_{4}$ solution appears to have the best parameters (high surface quality and etching rate $700 \mathrm{~nm} / \mathrm{min}$ ). However, this solution is selective, so it is only useful for etching indium phosphide. Also, during the etching process some problems arrived due to gassing effect. An attempt to solve this problem using ultrasound failed due to irregular etch rate over the entire surface of the substrate. 


\subsection{Epitaxial regrowth on patterned sub- strates}

Application of InP/InGaAs 'sandwich' instead of single indium phosphide layer allowed us to see in SEM cross-sectional images how the growth proceeds on various areas. These observations helped us to define directions and decide which slope shape is the most promising for future applications. A very important observation is that independently of the shape of mesas, epitaxial growth continuity has been preserved. Quality of interface between mesas and regrown structures seems to be good enough at this stage of studies, but in future research it will be thoroughly investigated.

\subsection{Summary}

The technology of wet chemical etching will be further developed. The property of etching mixture desired for application in QCL is its non-selectivity. Additionally, it would be the best if the shape of the slopes in $\langle 1 \overline{1} 0\rangle$ direction after etching process was concave. Another thing are the growth parameters. In both LP-MOVPE experiments the same recipe was used, so it is impossible to define at this moment the impact of various parameters on patterned substrate epitaxy results. That is why various epitaxial growth experiments still need to be performed to gain the knowledge about thin film deposition on nonplanar substrates.

\section{Acknowledgements}

This work was co-financed by the Wroclaw University of Technology Statutory Grant, the Polish National
Center for Research and Development under the Projects: No. PBS1/B3/2/2012 "EDEN", No. PBS2/A3/15/2013 "PROFIT". The Project "Interuniversity DidacticTechnological Center 'TECHNOPOLIS' in Wrocław" co-funded by the European Union from the funds of the European Regional Development Fund under the Infrastructure and Environment Program No UDA-POIS.13.01-021/09-00 is greatly acknowledged for SEM maps.

\section{References}

[1] Tanbun-Ek T., Logan R.A., Temkin H., Olsson N.A., Sergent A.M., Wecht K.W., IEEE Photonics Tech. L., 7 (1988), 453.

[2] Turco F.S., Tamargo M.C., Hweng D.M., NAhory R.E., Werner J., Kash K., Kapon E., Appl. Phys. Lett., 56 (1990), 72.

[3] Miller B.I., Koren U., CAPIK R.J., Electron. Lett., 18 (1986), 947.

[4] Ida M., Yamahata S., Kusishima K., Ito H., Kobayashi T., Matsuoka Y., IEEE T. Electron. Dev. 11 (1996), 1812.

[5] Huang R.T, Jiang C.L., Appelbaum A., RenNER D., ZEHR S.W., J. Electron. Mater., 11 (1990), 1313.

[6] Galeuchet Y.D., Roentgen P., Graf V., Appl. Phys. Lett., 53 (1988), 2638.

[7] Mawatari H., Fukuda M., Matsumoto S.I., Kishi K., ITAYA Y., Microelectron. Reliab., 11 - 12 (1996), 1915.

[8] Galeuchet Y.D., Roentgen P., Graf V., J. Appl. Phys., 68 (1990), 516.

[9] Kuech T.F., Tischler M.A., Potemski R., Appl. Phys. Lett., 54 (1989), 910. 